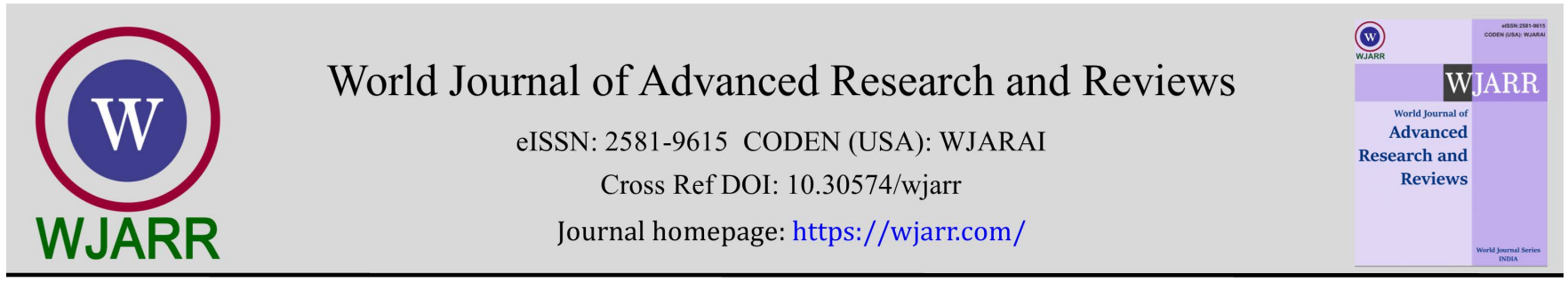

(RESEARCH ARTICLE)

Check for updates

\title{
Knowledge Level about Management of Social Media Use during the Covid-19 Pandemic
}

Moh. Ladrang Pramushinto Paramanindhito 1, Ezrin Syariman bin Roslan 1, Julian Benedict Swannjo ${ }^{1}$, I Putu Agus Arsana 1, Hersati Prasetyo 1, Mahrumi Dewi 1, Vatine Adila 1, Almara Diva Puteri Arnapi 1, Reyna Cesariyani Rahmadianti Rusuldi ${ }^{1}$, Idznika Nurannisa Wibowo ${ }^{1}$ and Danti Nur Indiastuti 2 ,*

${ }^{1}$ Medical Student, Faculty of Medicine, Universitas Airlangga, Surabaya, Indonesia.

2 Department of Anatomy, Histology and Pharmacology, Faculty of Medicine, Universitas Airlangga, Surabaya, Indonesia.

World Journal of Advanced Research and Reviews, 2022, 13(01), 261-265

Publication history: Received on 01 December 2021; revised on 04 January 2022; accepted on 06 January 2022

Article DOI: https://doi.org/10.30574/wjarr.2022.13.1.0002

\section{Abstract}

Introduction: Pandemic COVID-19 has led people to a new norm of spending most of their time at home. Regular direct physical social interactions become less common and replaced by interacting using social media.

Method: This is study is a descriptive survey, describing society's knowledge on the management of social media usage in COVID-19 Pandemic. 666 samples were gathered who met the inclusion and exclusion criteria. Google Form was spread amongst webinar participants, processed and distributed into tables, including average score based on age groups.

Results: Majority of the participants (69.5\%) achieved a score between 5-6 out of 7 questions that were given. Whilst, 0 participants received scores between 0 to 1 . Results achieved by all age groups are almost similar, with age $36-40$ appearing on top.

Conclusion: Knowledge regarding social media usage management does not appear to be affected by the person's age. This is because social media has been used by people of all ages, hence have almost similar knowledge regarding its usage.

Keywords: Low Birth Weight; Risk Factors; Chronic Energy Deficiency; Maternal Age; Antenatal Care Visits

\section{Introduction}

The COVID-19 outbreak has an impact on all corners of the world, including in Indonesia. Data shows that Indonesia currently has more than 3,194,733 positive confirmed cases as of July 26, 2021, with 84,766 of them dead. DKI Jakarta is a province with 794.937 confirmed cases, which is $24.9 \%$ of the total cases, followed by West Java (18.0\%) and East Java (11.2\%) [1].

Circumstances force people to adopt new norms to minimize direct human contact, including social distancing and working from home, or more commonly known as Work from Home (WFH) [2]. Daily social activities are also hampered, so the use of social media is among the best solutions to stay in touch while implementing new norms. Social media is an internet platform that emphasizes human interaction, which makes it easier for individuals to communicate, share

\footnotetext{
${ }^{*}$ Corresponding author: Danti Nur Indiastuti

Department of Anatomy, Histology and Pharmacology, Faculty of Medicine, Universitas Airlangga, Surabaya, Indonesia.

Copyright (@ 2022 Author(s) retain the copyright of this article. This article is published under the terms of the Creative Commons Attribution Liscense 4.0.
} 
and form online communities without the need to meet face-to-face [16]. The use of social media has a significant value in maintaining positive relationships among friends [3].

Kemp [4] obtained data showing that the use of social media in Indonesia increased by 10 million users, namely $6.8 \%$ during 2020-2021. It was found that the average Indonesian people spend 3 hours 14 minutes a day using social media. Most social media users are in the age range of 25 to 34 years, where the percentage of men is $14.8 \%$ and women $15.2 \%$. The use of social media in people with an age range of 18 to 24 years is also high, with a percentage of $15.9 \%$ for men and $14.8 \%$ for women [4]. Although social media is a solution for communication without requiring direct contact and implementing new norms, long-term use of social media can have a negative impact, especially on psychological wellbeing [5]. With the increasing number of users, the risk of the number of people experiencing the adverse effects of social media also increases.

In adolescents social media has a small negative impact on overall well-being [6]. The negative impact experienced by adolescents, generally experienced because they spend a lot of time on social media, is that they are more prone to anxiety and depressive moods [7].

Educational activities using the webinar platform via Zoom are very important because the Indonesian people have a very small interest in reading, which is $0.001 \%$. Public education through video media or webinars has proven to be effective in people of all age groups [8,9]. Therefore, we are interested in carrying out education related to how to use social media properly in the era of the COVID-19 pandemic.

\section{Material and methods}

This study is a descriptive survey study to assess the level of public's knowledge on the management of social media usage during the COVID-19 pandemic. This study was conducted on July 11, 2021 through an online webinar broadcasted through Zoom Meeting and Youtube. Sampling method that was used is total sampling. The online webinar is open to the public throughout Indonesia. Knowledge test were handed out to the webinar participants via Zoom meeting, live Youtube and participants' Whatsapp groups. Inclusion criteria in this study includes willingness to fill out a google form and aged between 12 to 55 years. Meanwhile, the exclusion criteria were respondents who did not fill out the google form completely. Primary data obtained through the google form. The data includes name, age, gender and true or false questions in order to evaluate their knowledge on management of social media usage during the COVID-19 pandemic. The data is then processed, and shown in tables to describe the demographics characteristics, average result per age group and interval data.

\section{Results and discussion}

Demography characteristics from respondents show age, gender and last education. Table 1 shows the distribution of respondents by their age and gender. The youngest respondent aged 12 years old, while the oldest aged 55 years old. Majority of the respondents are between the age of 16 to 20 years old, with a total of 495 of respondents (74, 32\%). The youngest age group in this study ranged between 12 to 15 years old with 56 respondents (8, 41\%). The total respondents that filled the form is 666 with 596 of them women and 70 of them men.

Table 2 shows the average result achieved by each age group. Age group were divided into 9 groups, with a range of 4 years each. Average score were divided into 2 scales, which are out of 7 and out of a 100. Age group with the highest score is between 36 to 40 years old (65.71\%), while the lowest is age between 12 to 15 years old (54.85\%). Meanwhile, three different age groups have achieved the same average score (57.14\%) There were no respondent aged between 46 to 50 years old.

Table 3 shows the interval data of the knowledge test, which is the total amount of respondent achieves their respective scores. 17 respondents achieved a perfect score. Majority of the respondent scores between 4 to 5 , while no respondent scores between 0 to 1 .

Nowadays social media have already penetrated our lives from education to health [10, 11]. 58\% of 47 million Indonesian citizens that have smartphones are teenagers aged 14 to 17 years old [12]. In 2018, research conducted in the United States of America shows that a majority of adolescents (95\%) have access to handphones at home [13]. This data is in accordance with our participant's target that can be seen to be focused on the age group 16 - 20 years old with 495 participants in total. Most of the attendees are around the age of 16 - 20 and 21 - 25 years old, where they are at the age of developing their sense of self [14]. That causes them to be susceptible to the negative sides of social media [15]. 
Women according to Demircioğlu and Göncü Köse [16] have a tendency to experience social media addiction when compared to men. Women emphasize more towards relationships than men and often use social media as a media of interaction. [17; 18]. Men on the other hand mainly use social media for entertainment and recreation, while women also use them for information [19].

In Indonesia, junior high school student (SMP) normally aged between 13-15 years old, while senior high school student (SMK/SMA) aged between 15 to 18 years old. According to Rules of Ministry of Education and Culture no. 14 year 2018 [20], the limit age of a senior high schoolers is 21 years old. Research conducted by Andarwati [21] regarding the usage of social media on second year high school students from SMA Negeri 9 Yogyakarta shows a high result, which is that $76 \%$ of students are counted as high category in social media use. This is caused because the majority of teenagers assume that the more active they are on social media, then the more they will look cool and trendy. Meanwhile, teenagers that do not have social media will look lame or not up to date [22]. Adolescents however, as one of the users of social media, are still not able to choose beneficial activities. They also have a tendency to be easily affected by their social life on social media, without looking whether the impact will be positive or negative [23]. Survey results from Association of Indonesian Internet Service Provider (APJII) [24] shows that the most used services accessed by internet users are chatting applications and social media that reach $89 \%$, followed by search engines, looking at photos, emails and banking. The survey also shows that 79, 23\% of internet users categorized by education are at S1/Diploma level [24].

Table 1 Distribution of Respondents' Characteristics, including Age and Gender

\begin{tabular}{|l|c|c|}
\hline Demographics Characteristics & \multicolumn{2}{|c|}{ Respondent (n = 666) } \\
\cline { 2 - 3 } & f & \% \\
\hline Age (years old) & 56 & 8.41 \\
\hline 12 - 15 & 495 & 74.32 \\
\hline $16-20$ & 97 & 14.56 \\
\hline $21-25$ & 7 & 1.05 \\
\hline $26-30$ & 3 & 0.45 \\
\hline $31-35$ & 5 & 0.75 \\
\hline $36-40$ & 2 & 0.30 \\
\hline $41-45$ & 0 & 0 \\
\hline $46-50$ & 1 & 0.15 \\
\hline 51 - 55 & \multicolumn{2}{|c|}{} \\
\hline Gender & 70 & 10.51 \\
\hline Female & 596 & 89.49 \\
\hline Male & \multicolumn{2}{|l|}{} \\
\hline
\end{tabular}

Table 2 Average Knowledge Test Scores by Age Group

\begin{tabular}{|c|c|c|}
\hline \multirow{2}{*}{ Age (years old) } & \multicolumn{2}{|c|}{ Average Score } \\
\cline { 2 - 3 } & Scale out of 7 & Scale out of 100 \\
\hline $12-15$ & 3.84 & 54.85 \\
\hline $16-20$ & 3.97 & 56.71 \\
\hline $21-25$ & 3.94 & 56.26 \\
\hline $26-30$ & 4.43 & 63.26 \\
\hline $31-35$ & 4 & 57.14 \\
\hline $36-40$ & 4.6 & 65.71 \\
\hline $41-45$ & 4 & 57.14 \\
\hline $46-50$ & 0 & 0 \\
\hline $51-55$ & 4 & 57.14 \\
\hline
\end{tabular}


There has been no research so far on the knowledge level of social media use so far, but a survey has said that students have the highest knowledge regarding social media followed by housewives and consultants [25]. However our results show a difference where the highest score is achieved by the 36 - 40 years old age group. Media social have been used by everyone from every age group, and usually only differentiated by their tendency and the type of media they use [26]. That is why in Table 2. That shows the average knowledge test results categorized by age are all similar.

Generally all participants answered the knowledge test with a good result, which is almost the highest interval at 4-5 with 463 participants in total. There are no participants with no knowledge about social media use management, shown by 0 - 1 intervals have no participants. This is because social media use has reached the public in every age group from 10 to 70 years old and older shown by a survey conducted by APJII survey : 2019 - 2020 (Q2) (2020), it also shows that internet use has penetrated $73,7 \%$ of the public, which is a rapid increase when considering in 2018 it was still $64,8 \%$ [25].

Table 3 Knowledge Test Result Interval Data

\begin{tabular}{|c|c|}
\hline Interval Score & Average Score \\
\hline $0-1$ & 0 \\
\hline $2-3$ & 171 \\
\hline $4-5$ & 463 \\
\hline $6-7$ & 32 \\
\hline
\end{tabular}

\section{Conclusion}

Generally, people have known the management of social media use as shown by the overall good results. Knowledge regarding social media use does not depend on age according to knowledge test data categorized by each age group. Social media users are not only young people, but also older people.

\section{Compliance with ethical standards}

\section{Acknowledgments}

This article could not have been possible without the assistance of many special people. We would like to thank Dr. Purwo Sri Rejeki, dr, M. Kes as the head of the KKN-Covid Module and dr. Danti Nur Indiastuti as our supervisor for the continuous assistance and support. Special thanks to Ester Chateline for her interactive presentation during the webinar. Last but not list, we would like to express our deepest appreciation to all members of group $5 \mathrm{KKN}-\mathrm{Covid}$ Module for the conscientious and diligent work throughout the whole activity.

\section{Disclosure of conflict of interest}

There is no conflict of interest in this study.

\section{Statement of ethical approval}

This study implemented the principle of Helsinki Declaration and followed basic principles of ethic.

\section{Statement of informed consent}

Inform consent was included in the first google formular page.

\section{References}

[1] Kominfo. Status COVID-19 Di Indonesia. 2021.

[2] Wilder-Smith, A, dan Freedman, D. O. Isolation, Quarantine, Social Distancing and Community Containment: Pivotal Role for Old- Style Public Health Measures in the Novel Coronavirus (2019-nCoV) Outbreak. Journal of Travel Medicine. 2020; 27(2): 1-4.

[3] Schmidt G, Lelchook A. dan Martin. The Relationship between Social Media Co-worker Connections and WorkRelated Attitudes. Elsevier. Computer in Human Behavour. 2016; 55: 439-445. 
[4] Kemp S. Digital 2021: Indonesia. 2021.

[5] Sitepu E. Effect of Smartphone Intensity Usage towards the Level of Interpersonal Communication. Journal of Social Opinion. 2019; 4(1): 14-29.

[6] Orben A. Teenagers, screens and social media: a narrative review of reviews and key studies. Social Psychiatry and Psychiatric Epidemiology. 2020; 55(4): 407-414.

[7] McCrae N, Gettings S, dan Purssell E. Social Media and Depressive Symptoms in Childhood and Adolescence: A Systematic Review. Adolescent Research Review. 2017; 2(4): 315-330.

[8] Directorate General of Primary and Secondary Education and Ministry of Education and Culture. The Master Design of School Literacy Movement. Jakarta. 2016.

[9] Taheri S, M, Falahati, F, Radpour, A, Karimi, V, Sedaghat, A. and Karimi, M. Role of Social Media and Telemedicine in Diagnosis \& Management of COVID-19; an Experience of the Iranian Society of Radiology. Archives of Iranian Medicine. 2020; 23(4): 285-286.

[10] Greenhow C, Galvin SM, Staudt Willet KB. What Should Be the Role of Social Media in Education? Policy Insights from the Behavioral and Brain Sciences. 2019; 6(2): 178-185.

[11] Taheri S, M, Falahati, F, Radpour, A, Karimi, V, Sedaghat, A. dan Karimi, M. Role of Social Media and Telemedicine in Diagnosis \& Management of COVID-19; An Experience of the Iranian Society of Radiology. Archives of Iranian Medicine. 2020; 23(4): 285-286.

[12] Nasution JA, Suhaili N, Alizamar A. Student's Motives in Owning Smartphone and its Usage.. Jurnal Penelitian Pendidikan Indonesia. 2017; 3(2).

[13] Anderson M, Jiang J. Teens, Social Media, \& Technology. Pew Research Center website. 2018.

[14] Diananda A. Psikologi Remaja dan Permasalahannya. ISTIGHNA. 2019; 1(1): 116-133.

[15] Nesi J. The Impact of Social Media on Youth Mental Health. North Carolina Medical Journal. 2020; 81(2): 116-121.

[16] Demircioğlu Z, Göncü Köse A. Effects of attachment styles, dark triad, rejection sensitivity, and relationship satisfaction on social media addiction: A mediated model Current Psychology. 2018; 40(1): 414-428.

[17] Fujimori, A, Yamazaki, T, Sato, M, Hayashi, H, Fujiwara, Y, \& Matsusaka, T. Study on In- fluence of Internal Working Models and Gender Differences on Addiction of Social Network Sites in Japanese University Students. Psychology. 2015; 6: 1832-1840.

[18] Kim JH, Kim M-S, Nam Y. An Analysis of Self-Construals, Motivations, Facebook Use, and User Satisfaction. International Journal of Human-Computer Interaction. 2010; 26(11-12): 1077-1099.

[19] Noguti V, Singh S, dan Waller DS. Gender Differences in Motivations to Use Social Networking Sites. In Information Resources Management Association (Ed.), Gender Economics: Breakthroughs in Research and Practice (676691). Hershey, PA: IGI Global. 2019.

[20] Directorate General of Primary and Secondary Education and Ministry of Education and Culture. Rules of Ministry of Education and Culture no. 14 year 2018. 2018.

[21] Andarwati L. Self-Image from Intensity of Social Media Usage (Instagram) on Class XI Stdeunt from National Senior High School 9 Yogyakarta. Journal Student UNY. 2016; 5: 1-12.

[22] Suryani FL, dan Suwarti CHD. Instagram and Fashion (Case Study of the role of Social Media (Instagram) towards teenagers fashion trend through @ootdindo account Year 2014). 2014; 1-20.

[23] Ekasari P, Dharmawan H. Effect of socio-economy towards effect of internet towards in rural adolesecent. Jurnal Sosiologi Pedesaan. 2012; 06(01): 1 - 15.

[24] APJII dan Teknopreneur. Infography of Penetration and Behaviour of Internet User 2017. Ministry of Communication and Information. 2017.

[25] APJII dan Indonesia Survey Center. Survey Report Internet 2019 - 2020 (Q2). Ministry of Communication and Information. 2020.

[26] Gambo S, Özad B. The demographics of computer-mediated communication: A review of social media demographic trends among social networking site giants. Computers in Human Behavior Reports. 2: 100016. 